\title{
LA MEDIACIÓN EN EL ÁMBITO DE LA SALUD Y SU ROL EN LA RELACIÓN SANITARIA
}

\author{
MEDIATION IN THE FIELD OF HEALTH AND ITS ROLE IN THE \\ SANITARY RELATIONSHIP
}

\author{
DARÍO PARRA SEPÚLVEDA * \\ Prof. de Derecho Civil \\ Universidad de Talca \\ Talca, Chile \\ ANÍBAL OLIVARES VANETTI ** \\ Investigador \\ Universidad de Talca \\ Talca, Chile \\ CAMILA RIESCO MENDOZA \\ Investigadora \\ Universidad de Talca \\ Talca, Chile
}

\section{RESUMEN}

Se revisa en forma unitaria la mediación como mecanismo alternativo de resolución de conflictos en el ámbito sanitario, introducido por la Ley 19.966 de 2004 y posteriormente recogido en la Ley 20.584 de 2012, destacando los principales problemas jurídicos que hasta la fecha se han evidenciado, así como el rol que viene a desempeñar en la relación sanitaria en cuanto

\footnotetext{
* Abogado. Doctor en Derecho U. Carlos III de Madrid-España. Profesor de Derecho Civil, U. de Talca. El presente trabajo se enmarca en el Proyecto de Investigación Fondecyt $\mathrm{N}^{\mathrm{o}} 11160566$, titulado: "Los deberes del facultativo en la responsabilidad civil médica: análisis crítico, propuesta de sistematización y contenido”, del cual el autor Darío Parra, es investigador responsable. Correo electrónico: dparra@utalca.cl.

** Estudiante de Derecho de la Universidad de Talca. Asistente de investigación del proyecto Fondecyt $\mathrm{N}^{\circ}$ 11160566, titulado "Los deberes del facultativo en la responsabilidad civil médica: análisis crítico, propuesta de sistematización y contenido”. Correo electrónico: olivaresvanetti@gmail.com.

*** Estudiante de Derecho de la Universidad de Talca. Asistente de investigación del proyecto Fondecyt $\mathrm{N}^{\circ}$ 11160566, titulado "Los deberes del facultativo en la responsabilidad civil médica: análisis crítico, propuesta de sistematización y contenido”. Correo electrónico: camila.riescomendoza@gmail.com.
}

Artículo recibido para su revisión el 9 de abril de 2018, y aceptado para su publicación el 23 de mayo de 2018. 
instrumento y herramienta de búsqueda de solución de conflictos. Se plantea la necesidad de la introducción y desarrollo de habilidades comunicacionales en la relación clínica de manera de fortalecer la resolución de conflictos a través del establecimiento de la confianza, el respeto y la colaboración entre las partes, contribuyendo al alcance de acuerdos más satisfactorios que permitan que esta herramienta autocompositiva se erija como una real alternativa de solución de conflictos en materia sanitaria.

Palabras claves: Mediación, relación sanitaria, responsabilidad médica.

\section{ABSTRACT}

Mediation is fully reviewed as an alternative mechanism for resolution of conflicts in the health field, introduced by law 19.966 of 2004 and then collected in law 20.584 of 2012, standing out the main legal problems that have been manifested, as well as the role that comes to play in the sanitary relationship as a tool and as an instrument on the research for solutions. It's analyzed especially the linking between mediation's aims with the characteristics and nature of the sanitary relationship. Among the challenges of the referenced instrument, we found a need for introduction and development of communication skills so that the clinical conflict resolution methods gets stronger, through the establishment of trust, respect and collaboration between the involved to finally contribute to reach better and more satisfying agreements and solutions that allows this self-help tool becoming a real choice for conflicts resolution on sanitary scope.

Keywords: Mediation, sanitary relationship, medical liability.

\section{INTRODUCCIÓN}

La mediación como método alternativo de resolución de conflictos en materia de salud se estableció con controvertido carácter obligatorio a partir de la dictación de la ley 19.966, normativa que junto con establecer un régimen de garantías, donde se incluyen las denominadas Garantías Explícitas en Salud (GES), consagra entre sus artículos 43 a 55 un sistema previo y obligatorio de solución de aquellas controversias que, a raíz de una deficiente actuación asistencial puedan suscitarse entre pacientes y 
prestadores de salud, ${ }^{1}$ siendo uno de sus objetivos principales la disminución de la creciente judicialización que ya en esa época era patente en dicho ámbito. Se incorpora así esta especial modalidad de resolución de conflictos en forma obligatoria y previa a la interposición de acciones judiciales de carácter reparatorio ${ }^{2}$ por daños ocurridos con ocasión de una defectuosa atención en salud, modalidad que también puede estimarse basal respecto de la Ley 20.584, ${ }^{3}$ que viene a regular y reconocer los derechos y deberes que tienen las personas respecto de acciones vinculadas a su atención en salud, por cuanto se contempla claramente -artículo 37- la posibilidad de solicitar la apertura de un procedimiento de mediación que tenga por objeto la revisión de los reclamos y la solución de los conflictos que se originen en torno a los derechos y deberes en ella establecidos.

En la práctica, respecto de los asuntos que dicen relación con la responsabilidad en materia sanitaria, la mediación por daños en salud es una instancia administrativa, que entrega la posibilidad tanto a los usuarios del sistema de salud, como a los establecimientos asistenciales, privados y públicos, de solucionar aquellas controversias que se susciten a propósito de eventuales negligencias sanitarias y/o faltas de servicio, a través de un procedimiento de carácter voluntario y confidencial, en donde los interesados, guiados por un tercero ajeno al conflicto, buscan acercar posiciones primando el diálogo y la colaboración.

En un primer acercamiento, se señalará que esta forma de solución de conflictos se desarrolla extrajudicialmente y está a cargo del Consejo de Defensa del Estado si la reclamación de reparación de perjuicios va dirigida en contra de los prestadores institucionales de salud pública, y, por otro lado, a cargo de un mediador privado registrado en la nómina correspondiente de la Superintendencia de Salud, si dicho reclamo va dirigido en contra de prestadores institucionales de salud privada.

\footnotetext{
${ }^{1}$ Si bien en la Ley 19.966 se establece la obligatoriedad del procedimiento de mediación previo en materia de salud, cabe destacar que la citada normativa ha de complementarse con lo establecido en el Reglamento de Mediación en Salud, regulado por el Decreto № 47 del Ministerio de Salud, el cual fue publicado en el Diario Oficial el 23 de junio de 2005. Normativa que, junto con desarrollar los principios generales de la mediación en el ámbito de la salud, regula el procedimiento de mediación prejudicial establecido en la citada Ley 19.966.

${ }^{2}$ Cabe destacar que el requisito esencial para que una reclamación en contra de un prestador de salud, sea este público o privado, sea susceptible del procedimiento de mediación regulado en la Ley 19.966, es que dicha solicitud esté fundada en la existencia de un perjuicio para el paciente cuya ocurrencia tenga directa relación con una defectuosa prestación de carácter asistencial.

${ }^{3}$ Milos HurTADO, Paulina; Siebel BierwirTH, Claudia, "El procedimiento de mediación establecido en la ley $\mathrm{N}^{\circ}$ 20.584”, Cuadernos de extensión jurídica, 2014, $\mathrm{N}^{\circ}$ 25, p.106. Los autores anotan diferencias sustanciales más que procedimentales.
} 
Erigiéndose como criterio diferenciador el carácter de privado o público del prestador de servicios sanitarios cuya defectuosa atención se reclama.

\subsection{Objeto y ámbito de aplicación de la mediación}

Del análisis de la normativa vigente cabe concluir que sólo serán objeto de mediación aquellos reclamos interpuestos por los interesados en contra de prestadores de salud, sean estos públicos o privados. Las reclamaciones esgrimidas por los solicitantes deberán estar fundadas principalmente en tres cuestiones: i) la existencia de un perjuicio susceptible de ser reparado desde la perspectiva civil; ii) la existencia de una defectuosa atención sanitaria por parte del prestador de salud o sus dependientes o funcionarios; y iii) la existencia de un claro vínculo causal entre la defectuosa atención sanitaria y el daño producido al solicitante.

Desde la perspectiva del daño susceptible de reparación en sede civil, debemos indicar que la Ley 19.966 en su artículo 41 expresamente incluye al denominado daño moral ${ }^{4}$ dentro de los perjuicios susceptibles de indemnización, y si bien no se avanza en un concepto que delimite este tipo de perjuicio extrapatrimonial, sí entrega al juez ciertos criterios para la determinación del quantum indemnizatorio ${ }^{5}$ los que permiten recoger un concepto más amplio de esta especie de perjuicios, posibilitando la apertura a nuevas categorías de daños indemnizables dentro de los que se podría destacar el denominado perjuicio de agrado. ${ }^{6-7}$

${ }^{4}$ Denominación poco afortunada en nuestro concepto debido principalmente a las sombras que rodean este término. Sobre las numerosas críticas y dificultades que se presentan para entregar una noción de daño moral, véase a BARros Bourie, Enrique, Tratado de Responsabilidad Extracontractual, Editorial Jurídica de Chile, Santiago, 2006, p. 231; DíEz-PiCAzo, Luis, El escándalo del daño moral, Civitas, Madrid, 2008; en el mismo sentido, la española VICENTE Domingo, Elena, "El daño”, en: Reglero, F. (ed.), Tratado de Responsabilidad Civil, Aranzadi, Navarra, 2008. pp. 346 se refiere a la instrumentalización del daño moral, el que para esta autora en muchos casos es utilizado como un simple comodín, como una pieza móvil.

${ }^{5}$ Ley $\mathrm{N}^{\circ}$ 19.966, 2004. Artículo 41: “La indemnización por el daño moral será fijada por el juez considerando la gravedad del daño y la modificación de las condiciones de existencia del afectado con el daño producido, atendiendo su edad y condiciones físicas”.

${ }^{6}$ Pizarro Wilson, Carlos, La responsabilidad civil médica, Legal Publishing Chile, Santiago, 2017, pp. 169 y 170.

${ }^{7}$ El préjudice d'agrément, consistente en la pérdida o limitación de satisfacciones de la vida que la persona lesionada tenía o podía tener normalmente, antes de la ocurrencia del acto dañoso, ha sido llamada en la doctrina francesa como pérdida de agrado, amenidad o préjudice d'agrément. En una etapa inicial este perjuicio era sólo indemnizable para aquellos que, por su particular actividad, tenían condiciones para disfrutar de ciertos goces, diversos de los que una persona común obtiene de la vida. Sin embargo, actualmente en Francia ha sido abandonada la limitación mencionada, por lo que ahora, con la noción de préjudice d'agrément cualquier persona lesionada puede demandar la reparación de la limitación que sufre en los placeres o goces usuales de la vida. Sobre el particular, véase a Domínguez ÁguiLA, Ramón, “Consideraciones en torno al daño en la responsabilidad civil: Una 
Respecto de la segunda cuestión, es menester indicar que lo que se indica como una defectuosa atención sanitaria proporcionada por el prestador de salud, sea público o privado, se identifica con la noción de culpa civil. De esta forma, si bien es cierto que nuestra legislación emplea términos diferentes al momento de referirse a este elemento de la responsabilidad en el ámbito del derecho público, es importante señalar que en lo que respecta a la responsabilidad de la administración del Estado a través de sus órganos, aquello que se conoce como falta de servicio es un concepto que se identifica plenamente con la noción de culpa abrazada en el ámbito civil, la cual permite atribuir responsabilidad al servicio público de salud en cuestión, de manera que nos parece zanjada la otrora discusión acerca de si el concepto falta de servicio evocaba una responsabilidad de índole estricta u objetiva, ${ }^{8}$ de modo que la sola acción u omisión del servicio que causaba un daño fuera suficiente para configurar la responsabilidad civil en cuestión, debiendo a nuestro juicio necesariamente probarse que en dicha acción u omisión dañosa ha mediado negligencia o culpa por parte del reclamado, lo que en terminología de responsabilidad del Estado, deviene en demostrar que el servicio prestado se apartó del estándar esperado y normal de funcionamiento, no funcionó debiendo hacerlo, o funcionó tardíamente o en manera defectuosa; en otras palabras, que la actuación del servicio se apartó del patrón deseable de conducta. Así lo ha venido resolviendo la jurisprudencia en innumerables ocasiones. ${ }^{9}$

Ahora bien, si la mediación se solicita en conformidad al artículo 37 de la Ley 20.584 de manera de hacer efectivos los derechos que la ley reconoce a los pacientes, el referenciado reclamo deberá fundarse en haberse producido un daño como consecuencia de conductas o acciones contrarias a los derechos y a la dignidad de las personas, debiendo además, diferenciarse el periodo o momento en que se produce el daño a la víctima, de modo que las conductas objeto de reclamación que se sujetan a la mediación establecida por la Ley 19.966 deberán acaecer como consecuencia de una prestación de salud, mientras que la conducta reclamada a que hace referencia la Ley 20.584 se verificará en aquel periodo denominado atención en salud, ${ }^{10}$ que a nuestro juicio, son situaciones y

visión comparatista”, Revista de Derecho Universidad de Concepción, 1990, № 188, p. 159; VINEY, Geneviève; Jourdain, Patrice, Traite de droit civil: Les effets de la responsabilité, L.G.D.J, Paris,

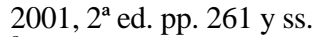

${ }^{8}$ PizARRo, cit. (n. 6), pp. 157 y 162.

${ }^{9}$ Al respecto, consultar: Corte de Apelaciones de Santiago, 19 de mayo de 2010, Rol No 4046-2009; Corte de Apelaciones de Santiago, 8 de julio de 2008, Rol N 23760-05; Corte de Apelaciones de Concepción, 22 de enero de 2009, Rol N 4651-2005.

${ }^{10}$ Milos y SiEBel, cit. (n. 3), p. 103. 
periodos verificables en la relación sanitaria que pueden coincidir en innumerables ocasiones, pero que a pesar de las sutilezas, pueden diferenciarse.

El sistema de mediación en comento implica que el solicitante, previo a recurrir a los tribunales de justicia, y siempre que se trate de aquel reclamo que tenga por objeto un daño producido como consecuencia de una prestación de salud, haya pasado por una instancia de mediación y que esta resulte frustrada, supuesto que, por lo demás, está previsto en la ley de forma bastante amplia y que se materializa en una certificación que acreditará la situación de no haber podido arribar a acuerdo las partes, sea por imposibilidad de acercamiento de posiciones, o debido a la incomparecencia reiterada de estos.

Así, tanto la Ley 19.996 como su reglamento señalan que sólo serán susceptibles de mediación aquellos reclamos deducidos por los interesados en contra de prestadores públicos de salud, sus funcionarios, o de prestadores asistenciales privados, cuando estos se funden en haber sufrido daños ocasionados a raíz de defectuosas prestaciones de carácter asistencial.

Del tenor de la normativa referenciada, cabe concluir que el comentado procedimiento autocompositivo se establece como previo y obligatorio para aquellas acciones que busquen indemnizaciones y/o compensaciones de perjuicios desde una perspectiva eminentemente civil.

Por otra parte, tratándose de la mediación cuyo objeto es el reclamo contra el prestador de salud que ha obrado en menoscabo de los derechos que la Ley 20.584 reconoce a las personas, su ámbito de aplicación según lo dispuesto en su artículo 37 viene a ser facultativo, y en cierta medida, una alternativa más de las que la ley reconoce a los afectados para dar solución al conflicto sanitario suscitado, de manera que la ley también ha establecido como cauce adecuado para ello el reclamo directo ante el prestador institucional aludido y la Superintendencia de Salud.

\subsection{Fines}

Como cuestión previa, nos parece relevante tener en cuenta el contexto en que se producen y desarrollan los tipos de conflictos que nos ocupan, puesto que las particularidades de la relación sanitaria condicionan estos últimos en su naturaleza, debiéndose tener siempre en consideración todos estos factores en cuanto a idear un sistema de resolución de conflictos exitoso que permita ser percibido por las partes como una real herramienta y alternativa. 
Así las cosas, nos parece relevante destacar que aun cuando la moderna mirada de la relación médico-sanitaria ha ido evolucionando con el paso de los años, pasando de una concepción absolutamente paternalista a una de respeto de la autonomía de los pacientes, ${ }^{11}$ no es menos cierto que en muchos aspectos dicha relación sigue manteniendo la tradicional asimetría que ha caracterizado por siglos al ejercicio de la actividad curativa. Nos referimos a las particularidades técnicas y científicas del arte médico que en gran medida resultan incomprensibles para un paciente que acude al profesional sanitario aquejado por una patología, ${ }^{12}$ circunstancias que al momento de producirse el conflicto no hacen más que oscurecer las posibles vías de solución entre las partes, implantando un cierto manto de impunidad y desconfianza que en la solución del conflicto nada aporta.

En segundo lugar, podemos avizorar al paciente junto a su entorno familiar, quienes, por regla general, acuden a los servicios de salud en condiciones adversas producto de la patología que los aqueja, lo que conlleva un estado anímico disminuido, el cual se verá mucho más afectado si al anterior diagnóstico sumamos condiciones socioeconómicas de vulnerabilidad.

En seguida, y permitiéndonos hacer una distinción, se debe identificar aquella intervención sanitaria que se desarrolla en directa relación con el médico y los profesionales de la salud que brindan asistencia al paciente, de aquel acercamiento que se produce en la relación entre la administración del centro asistencial y el paciente, configurándose una relación despersonalizada, indirecta y altamente burocratizada con este último.

A los puntos ya señalados cabe sumar el conflicto en sí mismo, que envuelve y condiciona las relaciones de los interesados, limitando el ámbito de actuación de cada sujeto. En suma, la realidad no hace más que mostrarnos una delicada situación donde se hace latente la necesidad de ofrecer a los ciudadanos una alternativa viable y rápida a la judicialización, cubierta por un marco normativo que resguarde el debido proceso, la igualdad y el respeto entre las partes involucradas para que éstos, en atención a las particularidades de la relación médico-paciente, puedan arribar a verdaderas soluciones de sus conflictos en materia sanitaria.

${ }^{11}$ Sobre la materialización de dicha evolución, con especial énfasis en el deber de entrega de información que pesa sobre el facultativo, véase a PARRA SEPÚlVEDA, Darío, "La obligación de informar al paciente. Cuestiones sobre el derecho a ser informado”, Revista Médica de Chile, 2013, Vol. 141, N 12, pp. 1578-1583.

${ }^{12}$ Calvo Rigual, Fernando; Costa Alcaraz, Ana M.; García-Conde Brú, Javier; Megía Sanz, $\mathrm{M}^{\mathrm{a}}$ Jesús, "Sin reconocimiento recíproco no hay calidad asistencial", Revista Española de Salud Pública, 2011, Vol. 85 № 5, p. 461. 
En orden de las ideas anteriores, y al tenor de la historia de la ley, cabe precisar que este método autocompositivo, en nuestro país, se concibió con el fin de desjudicializar los conflictos por daños en salud, limitar los montos indemnizatorios y brindar a los afectados un acceso expedito a la justicia, permitiéndoles participar activamente en la búsqueda colaborativa de soluciones a sus conflictos.

En este sentido, dicho mecanismo propone como objetivos la resolución y reconciliación. La resolución en tanto conclusión de la controversia con detalles y acuerdos llegados luego del intercambio de posiciones sobre un determinado asunto, pudiendo arrojar como resultados, por ejemplo, una compensación monetaria, disculpas públicas, prestaciones en servicios, entre otras. Por otro lado, se destaca la reconciliación como manifestación de restauración de la armonía entre las personas de un modo satisfactorio y duradero para los involucrados, adquiriendo ésta un especial sentido en materia de salud, por cuanto debido a las especiales características de la atención sanitaria, la relación médico-paciente se ve considerablemente mejorada cuando priman valores como la cercanía, la confianza y permanencia. ${ }^{13-14}$

\subsection{El Mediador}

El mediador es la persona que, actuando como tercero imparcial, tiene la responsabilidad de guiar el procedimiento de mediación, promoviendo un acercamiento de las posiciones de las partes a fin de que estos puedan lograr un acuerdo, bajo principios de: igualdad, celeridad, confidencialidad, imparcialidad, voluntariedad y probidad, entre otros.

Sobre la designación del mediador existen reglas diversas según la calidad de público o privado del prestador de servicios sanitarios reclamado, siendo irrelevante el sistema de salud al que se encuentre afiliado el afectado (ISAPRE o FONASA).

Así, en los casos en que el prestador de salud sea público, el o los mediadores serán designados por el Consejo de Defensa del Estado, organismo que a través de sus procuradurías fiscales cuenta con una red de mediadores que cubren la totalidad del territorio nacional, ciñéndose a lo establecido en los artículos 5 al 8 del Decreto $N^{\circ} 47$ del Ministerio de Salud de 23 de junio de 2005.

\footnotetext{
${ }^{13}$ Milos y Siebel, cit. (n. 3), pp. 105 y 106.

${ }^{14}$ Sobre la evolución de la relación médico-paciente puede verse a PARRA SEPÚLVEDA, Darío, "La evolución ético-jurídica de la responsabilidad médica”, Acta Bioethica, 2014, Vol. 20 N² 2.
} 
Por su parte, para los casos en que el requerido sea un prestador de salud privado, el solicitante deberá presentar su solicitud directamente ante la Superintendencia de Salud, procediéndose a la designación de un mediador de común acuerdo por los interesados (paciente solicitante y servicio de salud privado requerido), según el procedimiento establecido entre los artículos 9 al 13 del citado Decreto del Ministerio de Salud. Asumiendo los interesados, además, el costo íntegro del procedimiento de mediación. ${ }^{15}$

\section{LA MEDIACIÓN COMO INSTANCIA ADMINISTRATIVA FORZADA EN MATERIA DE SALUD}

La necesidad de garantizar el acceso a la justicia a todas las personas ha sido móvil en los distintos procesos de reforma judicial donde se ha incentivado la utilización de métodos alternativos de resolución de conflictos. En este sentido, dentro de las problemáticas que el legislador ha asumido y decidido ocuparse a través de un conjunto de medidas, ha considerado especialmente las condiciones de celeridad y formas que históricamente han limitado el accionar de las víctimas. Así, la lentitud de los procesos, su excesivo formalismo y su carácter sobradamente adversarial se configuran como características de una justicia anacrónica, despersonalizada y elitista. Es en este contexto que la inserción de la mediación en materia de salud aparece, a priori, como mecanismo que viene a dar respuesta a una necesidad ciudadana de herramientas jurisdiccionales más democráticas y efectivas.

Ahora bien, asumiendo la naturaleza obligatoria de la mediación en salud, y su establecimiento como requisito previo e imperativo para demandar la indemnización de perjuicios, se debe analizar la extensión de esta y los presupuestos para que constituya un requisito previo a accionar judicialmente.

Debemos señalar que no es nuevo el establecimiento de instancias de autocomposición concebidas como requisito obligatorio para accionar judicialmente. En este sentido, se constata que, al establecer este mecanismo colaborativo como una obligación ineludible e imperativa, el

${ }^{15}$ Cabe destacar que este organismo cuenta, a marzo de 2018, con 229 mediadores privados registrados a lo largo de todo chile. Los honorarios de los mediadores por el respectivo proceso de mediación fluctúan entre los 130.000 y 220.000 por proceso, siendo la media 150.000 aprox., al respecto véase: "Registro de Mediadores con Prestadores Privados - Por $\mathrm{N}^{\circ}$ de registro", documento .html, página web de la Superintendencia de Salud (Chile), disponible en línea: http://www.supersalud.gob.cl/acreditacion/673/w3-propertyvalue-6166.html, 21 de marzo de 2018. 
rol de la voluntad, de la libertad de iniciativa de someterse al proceso y de la amplitud de consenso entre las partes, ha sido dejado de lado y más bien viene a decaer, jugando un papel restringido y forzado.

Sin embargo, no se debe olvidar que la noción de obligatoriedad de esta instancia, de naturaleza eminentemente voluntaria, encuentra fundamento en la intención del legislador de descongestionar el sistema judicial y entregarles a los interesados una importante herramienta de solución de sus conflictos en sede extrajudicial. Para ello se instituyó este mecanismo, teniendo en cuenta la actual saturación del sistema y el objeto de brindar soluciones más rápidas y amigables a los intervinientes.

No obstante, el objetivo buscado por el legislador lamentablemente no ha sido logrado. Prueba de ello son los alarmantes resultados que pueden observarse a partir de las estadísticas que entrega tanto la Superintendencia de Salud, ${ }^{16}$ como el Consejo de Defensa del Estado. ${ }^{17}$ Así, en el sector público se han tramitado 7.937 procesos en diez años. De ellos, 651 han terminado en acuerdos que llevaron a hospitales y al Fisco a pagar \$ 4.960 millones. Luego, en el área privada, en diez años se han realizado 4.458 mediaciones, con una escasa tasa de acuerdos entre reclamantes y centros asistenciales privados. Las cifras indican que en el $44,7 \%$ de los casos el proceso de mediación ni siquiera se ha llevado a cabo, declarándose frustrado, y en el $40,8 \%$ de los casos, pese a desarrollarse un proceso de mediación, no se ha arribado a acuerdos entre las partes. A lo anterior, cabe agregar que, como ya se adelantó, para los casos en que el prestador de salud sea privado, los gastos de mediación deben ser costeados por los mismos interesados, derivando en una limitación para accionar y siendo paradójicamente contrario a la intención inicial con que fue concebido este mecanismo.

Por su parte, para el caso de la mediación con prestadores públicos es posible plantear la duda sobre si realmente existiría una igualdad de condiciones entre las partes, por cuanto se está frente a un conflicto que se

\footnotetext{
${ }^{16}$ La estadística más actualizada que dispone la Superintendencia de Salud es la del año 2015, donde se señala que de un total de 4.458 solicitudes de mediación en materia de salud, sólo un 12\% logró un acuerdo a través de la mediación. Ver documento: "Estadísticas de Mediación con Prestadores Privados de Salud, Ley No 19.966, Período: 10 de Marzo de 2005 al 30 de junio de 2015”, documento en pdf. (8 p.), página web de la Superintendencia de Salud (Chile), disponible en línea: http://www.supersalud.gob.cl/documentacion/666/articles-12879_recurso_1.pdf., 21 de marzo de 2018.

${ }^{17}$ El Consejo de Defensa del Estado en la estadística anual del año 2016, da cuenta que, de un total de 1.068 reclamaciones recibidas en el periodo, sólo un 21,7\% terminaron en acuerdo a través de mediación. Ver documento: “Mediación por daños en Salud. Estadísticas”, 2016, archivo en pdf. (14 p.), página web del Consejo de Defensa del Estado (Chile), disponible en línea: http://www.cde.cl/gestion_institucional/wp-content/uploads/sites/11/2016/03/Estadistica_ums_2016.pdf, 21 de marzo de 2018.
} 
“soluciona” entre un particular y el Estado, actuando como mediador un funcionario que también forma parte del aparato estatal. ${ }^{18}$

Por último, al asumir la naturaleza previa y obligatoria de la mediación, cabe preguntarse cuál es la herramienta o medio procesal más pertinente para alegar la falta de este trámite. $\mathrm{Al}$ respecto cabe subrayar que los tribunales de justicia han aceptado tanto la excepción de corrección del procedimiento, así como la nulidad procesal como medios idóneos a efectos de paralizar el procedimiento hasta que se verifique la subsanación del respectivo vicio. ${ }^{19}$

\section{PROCEDIMIENTO DE MEDIACIÓN EN MATERIA DE SALUD}

En este apartado examinaremos la reglamentación existente respecto del procedimiento de mediación, regulación que se encuentra contenida en el ya referenciado Decreto $\mathrm{N}^{\circ} 47$ del Ministerio de Salud de 23 de junio de 2005 (en adelante "el reglamento"), el que establece el reglamento de mediación por reclamos en contra de prestadores institucionales públicos de salud o sus funcionarios y prestadores privados de salud.

Así, en primer lugar debemos señalar que el procedimiento de mediación se iniciará a solicitud del interesado, mediante la presentación del respectivo reclamo ante el Consejo de Defensa del Estado, tratándose de aquellas instituciones que son parte de la red asistencial de prestadores de servicios sanitarios designados en el artículo 16 bis del Decreto Ley $\mathrm{N}^{\circ}$ 2.763 de 1979, o ante la Superintendencia de Salud, si el reclamo se dirige en contra de algún prestador privado de servicios sanitarios. La antedicha solicitud debe cumplir con las menciones establecidas en el artículo 22 del reglamento, a saber:

a) Nombre completo, cédula de identidad, edad, profesión u oficio y domicilio del interesado.

b) Nombre completo, cédula de identidad, edad, profesión u oficio del representante, si fuere legalmente necesaria su intervención.

c) Motivo del reclamo, individualizando al prestador.

d) Peticiones concretas en contra del prestador, si fuera posible.

La mediación se desarrollará de acuerdo con el número de audiencias que fueren necesarias para cumplir con los fines y objetivos del

18 GutiÉRrez Araque, María José, “La mediación en salud y acceso a la justicia”, Revista de Derecho Consejo de Defensa del Estado, 2008, № 20, p. 120.

${ }^{19}$ CÁrdenas Villarreal, Hugo; Moreno Molinet, Jaime, Responsabilidad médica: Estándares jurisprudenciales de la falta de servicio, Legal Publishing Chile, Santiago, 2011, $1^{\text {a }}$ edición, pp. 24-27. 
procedimiento, así el mediador tendrá amplia libertad para sesionar con las partes en forma conjunta o por separado, debiendo informar en todo caso a la otra. La primera audiencia tendrá por objeto explicar e informar a las partes "la naturaleza y los objetivos de la mediación, de su duración y etapas y del carácter voluntario de los acuerdos que de ella deriven, y las ilustrará acerca del valor jurídico de dichos acuerdos". ${ }^{20}$

Ahora, respecto de la extensión de la mediación, y según se desprende del artículo 47 de la Ley 19.966 y de los artículos 5 al 13 del reglamento, el carácter de obligatoriedad del trámite alcanza solo la primera audiencia fijada por el mediador, por cuanto en esta misma, las partes en cualquier momento podrán expresar su voluntad de no perseverar en el procedimiento, e incluso, fijada la primera audiencia y constatada la incomparecencia de una o de ambas partes, -sin perjuicio de los supuestos de incomparecencia justificada que señala la misma ley- se levantará acta de lo ocurrido y ello será suficiente para frustrar este trámite.

En este entendido, al constatar que es posible desistir de esta etapa en un momento tan temprano como la primera audiencia, se puede apreciar que se ve bastante estropeado y frustrado el deseo del legislador de llegar a acuerdo, pues la consecución de esta instancia que fue concebida como obligatoria y necesaria, se ve reducida en la práctica a la constatación de la reclamación y respectiva certificación de no acuerdo o de mediación frustrada. La situación descrita deriva irónicamente en el retardo del derecho a accionar por parte de la víctima quién junto con asumir el perjuicio del que está reclamando, debe soportar la carga extra de un procedimiento de mediación respecto del cual existe una alta probabilidad -como así lo muestran las estadísticas-, que termine con una certificación de no acuerdo o de frustración de dicho procedimiento.

En relación con la comparecencia de las partes a las audiencias, la normativa exige que esta sea personal o por medio de representante legal en los casos que corresponda, no obstante, se permite que los intervinientes puedan designar a un apoderado con facultades expresas para transigir. En todo caso, y adicionalmente, las partes podrán ser asistidas por terceros. Si se verificare la incomparecencia de cualquiera de ellas en la primera audiencia, se citará a una segunda, entendiéndose fracasada la mediación de repetirse dicha incomparecencia, salvo que se acompañen dentro de tercero día antecedentes verosímiles que la justifiquen, citándose en este caso, por última vez a la primera audiencia. En caso de existir audiencias posteriores se procederá en la forma anteriormente descrita.

${ }^{20}$ Ley $N^{\circ}$ 19.966, de 2004. Artículo 47. 
Además, como manifestación del principio de confidencialidad, se establece el secreto de todas las declaraciones y actuaciones de la mediación, sin perjuicio que los instrumentos públicos o privados que se hayan acompañado estarán sujeto en su uso y valor probatorio en juicio a las reglas generales, no quedando afectos al secreto anteriormente referido.

Una última consideración respecto del procedimiento de mediación, según lo dispuesto en el artículo 35 del reglamento, es la amplia libertad que gozan las partes tanto en el arribo de acuerdos, como en la forma de cumplirlos, pudiendo pactarse al respecto el pago de compensaciones en dinero o apreciables en dinero. De conformidad a lo acordado, el mediador levantará un acta en que se deje constancia de los términos pactados, acta que producirá jurídicamente los mismos efectos de un contrato de transacción, el que según nuestra normativa civil se convierte en ley para las partes, sin que en este caso exista una instancia objetiva de revisión por parte de los tribunales de justicia, como ocurre por ejemplo con buena parte de las mediaciones en materia de familia. Asunto que plantea a lo menos alguna incongruencia si consideramos la creciente importancia que el legislador ha venido otorgando a los derechos del paciente y a las garantías en materia de salud.

\subsection{Examen de admisibilidad previo}

El reglamento, en su artículo 25, dispone un examen previo de admisibilidad del reclamo que da inicio al procedimiento de mediación. En esta etapa el Consejo de Defensa del Estado o la Superintendencia de Salud, según corresponda, verificará si el objeto de la solicitud es susceptible de someterse al procedimiento de mediación, la cual podrá ser desechada si notoriamente se refiriese a temáticas no mediables en los términos de la normativa en comento, resolución de la cual podrá el interesado pedir reposición dentro de quinto día hábil. En todo caso, se otorga al interesado la posibilidad de rectificar o aclarar todas las deficiencias relacionadas con las menciones mínimas que deberá contener el reclamo.

En este punto, conviene referirse a algunas de las interrogantes que se han esbozado con ocasión de la exigencia de la mediación como requisito previo del ejercicio de una acción jurisdiccional en esta materia. Así, no queda claro si el solo hecho de la interposición del reclamo cumpliría con la exigencia del legislador, de manera que bien podría pensarse que "el hecho de presentar el reclamo da por cumplida dicha exigencia de procesabilidad instaurada en la Ley $N^{\circ} 19.966$, aunque en definitiva no se 
desarrolle el procedimiento, siendo en esta instancia procedente la interposición de la respectiva acción jurisdiccional, ante la justicia ordinaria", ${ }^{21}$ en el mismo sentido "se ha observado que el solo hecho de presentar el reclamo tiene como efecto el cumplimiento de la exigencia de procesabilidad que establece la ley. De modo que declarada la inadmisibilidad del reclamo queda abierta la posibilidad de recurrir a los tribunales de justicia". ${ }^{22}$ Por otra parte, tampoco se tiene claridad respecto del efecto de la notificación de la resolución que acepta a tramitación el reclamo, así " $n i$ la ley ni el reglamento señalan si en estos casos se otorgará además el certificado de cumplimiento de mediación obligatoria que permita interponer la acción civil". ${ }^{23}$

\subsection{Suspensión de la prescripción}

A este respecto los artículos 45 de la Ley 19.966 y 31 del reglamento establecen una duración total del procedimiento de mediación de 60 días corridos, los que se contarán a partir del tercer día de la primera citación al reclamado, sin perjuicio de la prórroga por acuerdo de las partes hasta por 120 días. En su parte final, ambos preceptos establecen que durante el plazo que dure la mediación se suspenderá el término de prescripción, tanto de las acciones civiles como de las criminales a que hubiera lugar.

Uno de los problemas a que da lugar tanto la redacción del artículo 45 de la Ley 19.966, así como la del artículo 31 del reglamento, es que no señalan con claridad el momento o la época precisa en que se produce la suspensión de la prescripción de las acciones. En este sentido, la Corte Suprema ha resuelto que dicha suspensión se produce al momento de presentarse por parte del interesado el reclamo respectivo, mismo instante en que se da inicio al procedimiento de mediación en conformidad al artículo 22 del citado reglamento, entendiéndose que la mediación se inicia con independencia de producirse acuerdo en la persona del mediador. De esta forma, como bien ha señalado la Corte Suprema: "si bien no se establece con exactitud la época en que comienza a regir tal efecto, lo cierto es que tal determinación no puede sino que entenderse practicada desde que se inicia el procedimiento de mediación, el que conforme a lo dispuesto por el artículo 22 del referido Reglamento, ocurre 'por la

\footnotetext{
${ }^{21}$ GuTIÉRREZ, cit. (n. 18), p. 128.

${ }^{22}$ Milos y SiEBEL, cit. (n. 3), p. 100.

23 Ídem.
} 
presentación de un reclamo por el interesado’ y la consiguiente citación a los reclamados". ${ }^{24}$

\section{ALGUNAS CUESTIONES SOBRE SU CONSTITUCIONALIDAD}

La exigencia que las partes se sometan a un procedimiento de mediación previa como requisito de admisibilidad de la acción indemnizatoria por daños en el ámbito de la salud, no ha estado exenta de críticas al momento de analizar, entre otros aspectos, su controvertida naturaleza obligatoria y su consideración de trámite necesario de procesabilidad. Así, cierta jurisprudencia la ha estimado como un trámite de carácter imperativo que condiciona el ejercicio de ciertas acciones jurisdiccionales ${ }^{25}$ cuya omisión deviene en una irregularidad procesal que debe corregirse, ${ }^{26} \mathrm{y}$, por otro lado, cierta corriente ha estimado diferenciar la obligatoriedad como presupuesto de procesabilidad atendiendo contra quien se dirige el reclamo correspondiente. De este modo, tratándose de prestadores públicos de servicios sanitarios la obligatoriedad se fundamentaría en el interés público, mientras que la exigencia de mediación en el caso de los prestadores privados estaría estatuida en el interés individual del solicitante, no siendo procedente la nulidad de todo lo obrado en caso de ausencia. ${ }^{27}$

Uno de grandes vicios de inconstitucionalidad que ha sido alegado respecto de la normativa en estudio, es la restricción e incluso impedimento al ejercicio del derecho fundamental que se establece y emana del artículo 19 número 3 de nuestra carta magna, el cual ve enriquecido su contenido a través del artículo 5 inciso $2^{\circ}$ de la misma Constitución Política. La crítica surge de la consideración de un derecho a la tutela judicial efectiva que comprende garantías y derechos distribuidos en tres etapas, ${ }^{28}$ donde la primera de ellas corresponde al libre e igualitario acceso a la justicia, entendiéndose como tal a "...la potencia o posibilidad que toda persona, ante una vulneración de sus intereses legítimos, pueda tener las vías necesarias y eficaces- para poner en conocimiento de la competente autoridad la conculcación que reclama....”. ${ }^{29}$

\footnotetext{
${ }^{24}$ Corte Suprema, 21 de marzo de 2016, Rol N 31061-2014, considerando sexto.

${ }^{25}$ Corte de Apelaciones de Santiago, 9 de mayo de 2008, Rol № 4926-2007.

${ }^{26}$ Corte de Apelaciones de Concepción, 8 de octubre de 2007, Rol No 2903-2005.

${ }^{27}$ Corte de Apelaciones de Concepción, 20 de mayo de 2008, Rol N 211-2007.

${ }^{28}$ Palomo Vélez, Diego; Valenzuela Villalobos, Williams, "Descarte de la inconstitucionalidad de la obligatoriedad de la mediación prejudicial que establece la ley 19.966: lectura crítica de la sentencia del Tribunal Constitucional”, Revista Ius Et Praxis, 2012, año 18 N 2, p. 409.

${ }^{29}$ PALOMO y VALENZUELA, cit. (n. 28), p. 409.
} 
Sobre el particular, cabe destacar la crítica que se ha deslizado a la citada exigencia de procesabilidad, al estimarse que "posterga indebidamente a la jurisdicción y pone barreras de entrada demasiado onerosas para los derechos de los justiciables...”. ${ }^{30}$ En similar sentido, se ha destacado que la obligatoriedad de la mediación en salud "vulnera el debido proceso, puesto que constituye una barrera u obstáculo al ejercicio legítimo de los derechos y pretensiones de las partes, impidiéndoles actuar en forma efectiva, expedita y libre de trabas". ${ }^{31}$

En el sentido opuesto, el Tribunal Constitucional en sentencia dictada el 10 de julio de 2012, rechazó un requerimiento de inaplicabilidad por inconstitucionalidad respecto del artículo 43 de la ley en comento, en cuanto la actora consideraba que se lesionaba ,entre otros, la garantía constitucional de igual protección en el ejercicio de los derechos, estimando que la suspensión de la prescripción a que da lugar el inicio del procedimiento de mediación pone a salvo el ejercicio de las acciones jurisdiccionales. ${ }^{32}$

Sin embargo, se ha señalado que el acceso a la justicia no es libre e irrestricto, sino que es lícito imponer ciertos requisitos o condiciones que permitan acceder o activar el engranaje jurisdiccional, ${ }^{33}$ pero lo que no sería lícito es “...el establecimiento de obstáculos excesivos producto de un formalismo ritualista que no es coherente ni concordante con el derecho a la justicia, las formalidades deben ser sólo aquellas que aparezcan justificadas, legítimas y proporcionadas conforme a sus finalidades". ${ }^{34}$

En este sentido, cabe sostener que la obligatoriedad de la institución en comento podría devenir en una lesión al derecho de acceso a la justicia, en cuanto no parece idóneo restringir o limitar en forma excesiva, ni desviar el ejercicio del derecho de las personas a recurrir a los órganos jurisdiccionales que por mandato constitucional tienen la facultad de conocer las controversias de relevancia jurídica que en una sociedad democrática se produzcan, de suerte que, como consecuencia del predominio del Estado Constitucional de Derecho, se ha sustraído de los particulares la facultad de auto tutelar la resolución de sus conflictos, de

\footnotetext{
${ }^{30}$ Ibídem, p. 410.

${ }^{31}$ LeIVA LóPEZ, Alejandro, "Sobre la inconstitucionalidad de la figura de la "mediación” obligatoria contenida en el artículo 43 de la ley 19.966 (Comentario con ocasión de la sentencia del Tribunal Constitucional Rol 2042-2011 del 10 de julio de 2012)”, Revista de Derecho Público Iberoamericano, 2012, $\mathrm{N}^{\circ} 1$, p. 276.

${ }^{32}$ Tribunal Constitucional, 10 de julio de 2011, Rol N²042-2011, considerando trigésimo segundo.

${ }^{33}$ Palomo y ValenZuela, cit. (n. 28), p. 413.

${ }^{34}$ NogueIRa AlCalá, Humberto, El debido proceso en la Constitución y el Sistema Interamericano, Librotecnia, Santiago, 2012, p. 33.
} 
manera que es el Estado quien debe velar porque sus ciudadanos tengan acceso a los órganos jurisdiccionales de la manera más sencilla y oportuna posible, de acuerdo con lo previsto en la Convención Americana de Derechos Humanos. ${ }^{35}$

Así las cosas, la principal crítica a esta institución dice relación con el establecimiento de cargas para accionar que no parecen justificadas ni parecen estar establecidas para la acertada o adecuada resolución de conflictos jurídicos, lo que viene a exceder lo permitido por el constituyente al momento de regular el ejercicio de los derechos fundamentales reconocidos por él, de modo que no se tornen impracticables. ${ }^{36}$

En otro punto, cabe hacerse cargo de aquellas consideraciones que han estimado a la mediación en materia de salud como un mecanismo que cumple la función de acercar la justicia a quienes por consideraciones económicas o de diversa índole no tienen las posibilidades de proseguir un procedimiento ante instancias judiciales que les permita tutelar debidamente sus intereses. ${ }^{37}$ Dicho argumento pareciera no constituir la manera idónea de fundar el establecimiento del procedimiento de mediación obligatoria en instancias extrajudiciales, por cuanto reiteramos que más que un acercamiento a la justicia, en la práctica, la estudiada exigencia se ha transformado en una carga adicional que principalmente la víctima del perjuicio ha de asumir a efectos de obtener una reparación razonable del daño sufrido con ocasión de una defectuosa prestación de salud.

Por último, y con respecto a la instancia de mediación que se deberá desarrollar ante mediadores designados por el Consejo de Defensa del Estado, en aquellos casos en que la acción resarcitoria tenga como objetivo demandar la responsabilidad de prestadores públicos de salud, pareciera ser cuestionable que se obligue a la víctima a concurrir a una instancia extrajudicial a mediar lo que muchas veces supone un atentado contra su salud o derechamente su vida sin que exista un control judicial del acuerdo arribado entre la víctima y el establecimiento de salud, entregándole el control de dicho acuerdo exclusivamente al Consejo de Defensa del Estado cuando éste supere las mil unidades de fomento, impropiedad que se hace evidente al considerar que el mediador que está a cargo del procedimiento

\footnotetext{
35 Convención Americana de Derechos Humanos, Suscrita en San José de Costa Rica el 22 de noviembre de 1969 y publicada en el Diario Oficial el 5 de enero de 1991 (Decreto $N^{\circ}$ 873). Véase los Artículos 8.1 (Garantías Judiciales) y 25 (Protección Judicial).

${ }^{36}$ Palomo y ValenZUEla, cit. (n. 28), p. 414.

37 Vargas Pavez, Macarena, "Caso Pamela de las Mercedes Bahamondes Moreno. Tribunal Constitucional. Sentencia de 10 de julio de 2012”, Revista Chilena de Derecho Privado”, 2013, N 20, pp. 313-314.
} 
es un funcionario del mismo órgano que constituye la única instancia de revisión del acuerdo. ${ }^{38}$

\section{LA MEDIACIÓN DESDE LA PERSPECTIVA DE LA RELACIÓN MÉDICO-PACIENTE}

Como ya se ha señalado, en virtud de la reciente transformación que ha sufrido la relación médico-paciente, uno de los aspectos más importantes dice relación con el cambio y deterioro de la atmósfera y lazos de estrecha confianza existente entre el profesional de la salud y su paciente, como consecuencia, entre otros factores, de la inclusión de un nuevo elemento o sujeto de interacción en la relación sanitaria, a saber, el centro de atención médica (ya sea de carácter público o privado). Así, esta relación ha devenido en complejizarse y despersonalizarse, originando mayores cuotas de insatisfacción, descontento y confusión para la ciudadanía en cuanto a los servicios sanitarios prestados, lo que a nuestro juicio contribuye tanto al origen, como a la profundización del conflicto que se materializa en un sostenido aumento de la judicialización de aquellos conflictos originados en intervenciones médicas. ${ }^{39}$

En este sentido, cabe preguntarnos en qué medida los procesos de comunicación entre los actores de la relación sanitaria influyen en los procesos de búsqueda de soluciones que permitan la superación del conflicto y en consecuencia, la reparación o minimización del daño causado. Así, nos parece concordante con los fines de la justicia colaborativa aquel modelo de ejercicio de la actividad médica que descansa sobre la base del desarrollo de habilidades comunicacionales por parte del profesional de la salud, ${ }^{40}$ donde se construyen relaciones que tienen por características "el intercambio de información, la confianza, la sinceridad, el apoyo-ayuda, la personalización y el respeto". ${ }^{41}$ En este sentido, cabe destacar que si se logra el reconocimiento recíproco entre las partes involucradas en la relación sanitaria, disminuirán considerablemente las cuotas de conflictos que no solo se originan como consecuencia de la existencia de un perjuicio indemnizable, sino que en muchos casos suelen producirse a consecuencia de una suerte de instrumentalización y despersonalización del paciente.

\footnotetext{
${ }^{38}$ LeIVA, cit. (n. 31), p. 278.

${ }^{39}$ PARRA, cit. (n. 14), p. 208.

${ }^{40}$ CHARON, Rita, "Narrative medicine: A model for empathy, reflection, profession and trust, JAMA, 2001, Vol. $286 \mathrm{~N}^{\circ}$ 15, p. 1897.

${ }^{41}$ CARNEROS DE Blas, María, "Mediando en salud, una propuesta de mediación sanitaria en hospitales”, Revista de Mediación, 2012, N 5, p. 15.
} 
En el mismo orden de ideas, nos parece interesante recordar que las dificultades de comunicación que puedan presentarse en la relación médico-paciente serán determinantes a la hora que las partes deban enfrentar un conflicto, existiendo al respecto una relación directamente proporcional entre calidad de comunicación y solución de controversias. Es en razón de lo apuntado, que nos parece indispensable hacer hincapié en una comunicación de calidad entre médico y paciente con miras a impulsar interacciones más humanas y dignas en el ámbito clínico ${ }^{42}$ que permitan una mejor dirección y solución de los posibles conflictos que puedan presentarse con ocasión de una atención sanitaria.

Se pretende así centrarse mucho más en la gestión del conflicto con miras a que los protagonistas de éste se sientan motivados para buscar mejores métodos con los que obtener los resultados más óptimos dentro de sus posibilidades, lo que nos fuerza necesariamente a advertir que la buena gestión del conflicto comienza no solo con el inicio de un procedimiento de mediación, sino que ésta debe atenderse y desarrollarse en el origen mismo de éste, y aun antes de que se produzca, en una suerte de gestión preventiva de conflictos. ${ }^{43}$

A pesar de que parezca contradictorio, el conflicto no es necesariamente negativo. Puede afirmarse que un cierto nivel controlable o tolerable de conflicto puede generar consecuencias positivas, como estimular el nivel de diligencia en la prestación de servicios médicos y sanitarios, impulsar la prevención y ennoblecer la toma de decisiones, además de posicionar a los usuarios del sistema de salud, a los prestadores y al legislador en una posición autocrítica cuyos resultados impulsen a mejorar la comunicabilidad de la norma y el fin de la misma a partir del conocimiento acabado de las diferentes problemáticas que se dan en este ámbito. ${ }^{44}$

\footnotetext{
${ }^{42}$ Montaner Abásolo, M. Carmen; Soler Company, Enrique, "La relación con el paciente desde la perspectiva personalista. Saber comunicar, un imperativo ético”, Cuadernos de Bioética, 2012, Vol. $23 \mathrm{~N}^{\circ}$ 79, pp. 632-633.

${ }^{43}$ CARNEROS, cit. (n. 41), p. 17.

${ }^{44}$ En similar sentido se ha planteado que "el conflicto es como el agua: demasiada agua causa daños a la vida y a las cosas; demasiado poca da lugar a paisaje seco, desértico y sin vida ni color. Necesitamos agua para sobrevivir; también necesitamos un nivel apropiado de conflicto para prosperar y crecer. La manera en que manejamos nuestros recursos hídricos naturales por medio de diques, pantanos y esclusas, hará que logremos el equilibrio necesario para la vida. Lo mismo ocurre con el manejo de los conflictos: hay que lograr un equilibrio entre fuerzas opuestas e intereses enfrentados...”. Constantino, Cathy; Sickles, Christina, Diseño de sistemas para enfrentar conflictos, Granica, Barcelona, 1997, traducción de la primera edición por Gabriel Zadunaisky, p. 19.
} 
En relación con lo dicho, se debe apuntar que los conflictos no necesariamente dañan el funcionamiento de una organización ni implican que sus integrantes sean ineficaces, por el contrario, ellos fortalecen en gran medida el servicio prestado, pues el aspecto más positivo del conflicto es la salida a la superficie de problemas hasta entonces ocultos, lo que permite confrontarlos y resolverlos, perfeccionando la atención del servicio y la diligencia de sus funcionarios. $\mathrm{Al}$ respecto es importante que el sistema -siempre perfectible- esté a la altura de los fines que persigue. El desafío de la mediación en el sistema de salud es evitar que crezca la desconfianza entre las personas que deberían coordinar sus esfuerzos y tender a la celeridad y seriedad en la resolución del conflicto, ya que evitando su prolongación disminuye la frustración y hostilidad entre las partes propiciando acuerdos que den término al problema; lo anterior, sin perjuicio de las prevenciones resaltadas más arriba en cuanto a evitar una suerte de justicia que por mucha celeridad que se busque termine en privar de legítimos derechos a los interesados, como la igualdad en el acceso a la justicia o en la aceptación de acuerdos que perjudiquen los intereses de quien ya es una víctima, lo que se agudiza en mayor medida al no existir ninguna instancia de revisión judicial, como ya se ha dicho.

De esta forma, la implementación de la mediación en nuestro sistema presenta una doble utilidad en el ámbito sanitario: por una parte, nos encontramos con aquella orientada a precaver la judicialización de los daños producidos con ocasión de prestaciones de salud; y por otra, se erige como alternativa en aquellos casos en que los derechos de los pacientes se vulneran a consecuencia de la atención en salud. Es en este punto que creemos importante destacar el relevante papel que este mecanismo autocompositivo tiene en la solución de aquellos conflictos que, debido a las especiales características del conflicto en el ámbito sanitario y de la relación médico-paciente, no logran una satisfactoria respuesta en la vía judicial, resultando por ello ser una herramienta muy positiva en términos de mejorar la calidad del servicio de salud así como también la percepción de los involucrados en la relación médico-paciente. ${ }^{45}$

\section{CONCLUSIÓN}

Dada la necesidad de atender los conflictos de relevancia jurídica que se suscitan entre prestadores de servicios sanitarios y sus usuarios, destacamos la importancia de los mecanismos alternativos de resolución de

\footnotetext{
${ }^{45}$ CARNEROS, cit. (n. 41), p.17.
} 
conflictos en este ámbito, sobre todo si se tiene en consideración que la otrora relación médico-paciente ha devenido en complejizarse y despersonalizarse.

Sin embargo, y en concordancia con las opiniones expuestas en este trabajo, reiteramos que debe analizarse y revisarse con sumo cuidado el establecimiento y extensión de la obligatoriedad de este mecanismo en el ámbito sanitario, pues debe tenerse siempre en consideración la necesidad de respetar los derechos que nuestra carta fundamental reconoce a todas las personas, procurando que la imposición de recurrir a una instancia previa no resulte excesivamente onerosa para la víctima, o no le impida, o retarde, su legítimo acceso a la justicia ordinaria.

Además, con base en el análisis de las cifras expuestas, insistimos en la urgencia de admitir que este modelo no está teniendo en la praxis el impacto esperado. Ello en virtud de la bajísima tasa de acuerdos en que finalizan los procesos seguidos, de manera que no resulta difícil afirmar que actualmente la mediación en el ámbito de la salud no se presenta como una herramienta útil, ni alternativa eficiente a la vía judicial; por el contrario, al hablar de este método autocompositivo en materia asistencial, de inmediato surgen voces que lo catalogan como una obligación procesal o trámite necesario para la interposición de una acción judicial. ${ }^{46}$

En el mismo sentido, cabe apreciar que, si bien la baja tasa de éxito de los procesos de mediación responde a una serie de factores, no debemos desconocer la influencia que tiene la forma en que el paciente se relaciona con el centro asistencial y/o facultativo. Por cuanto, como se ha expuesto, la despersonalización, información deficiente, falta de empatía y la pérdida de confianza influyen poderosamente en la tasa de fracasos de una herramienta de búsqueda colaborativa de soluciones como lo es la mediación, de modo que vemos con muy buenos ojos la introducción y fiscalización de habilidades comunicacionales por parte de los prestadores sanitarios como un elemento de enriquecimiento de la relación sanitaria que coadyuve con procesos de diálogo, colaboración y confianza, para paliar los efectos de la relación asimétrica y de vulnerabilidad en que se encuentra el paciente, permitiendo a la mediación cumplir con sus fines de la manera más concordante con sus principios. Así, destacamos la poderosa influencia que estos cambios en la relación sanitaria pueden ejercer no solo en la resolución de un conflicto, sino también en su gestión temprana y, por lo tanto, prevención.

${ }^{46}$ Candia, Paola; Suazo Galdames, Iván, “Tasa de Éxito del Sistema de Mediación Prejudicial por Daño en Salud en Chile entre los años 2005 y 2009”, International Journal of Odontostomatology, 2011, Vol. 5 N³, pp. 300-303. 
Por último, se debe resaltar que la mediación en materia de salud implica una notable innovación, un procedimiento más sofisticado, más complejo, más técnico, más civilizado, más moderno, pero que necesariamente debe estar en constante perfeccionamiento. Es por ello que importa resguardar sus fines y replantearse, entre otros: a) la extensión de la obligatoriedad del procedimiento; b) los eventuales costos que debe asumir el reclamante; c) la necesidad de introducir o no la figura de un defensor del paciente, de manera que en el futuro la mediación se transforme en una real alternativa a la judicialización de los conflictos en el ámbito sanitario.

\section{BIBLIOGRAFÍA CITADA}

BARros Bourie, Enrique, Tratado de Responsabilidad Extracontractual, Editorial Jurídica de Chile, Santiago, 2006.

Calvo Rigual, Fernando; Costa Alcaraz, Ana M.; GarcíaCONDE BRÚ, Javier; MEGÍA SANZ, Ma Jesús, "Sin reconocimiento recíproco no hay calidad asistencial”, Revista Española de Salud Pública, 2011, Vol. 85, N 5, pp. 459-468.

CANDIA, Paola; SuAzo Galdames, Iván, “Tasa de Éxito del Sistema de Mediación Prejudicial por Daño en Salud en Chile entre los años 2005 y 2009”, International Journal of Odontostomatology, 2011, Vol. 5 N$^{\circ}$ 3, pp. 300-303.

CÁRdenas VillarReal, Hugo; Moreno Molinet, Jaime, Responsabilidad médica: Estándares jurisprudenciales de la falta de servicio, Legal Publishing Chile, Santiago, 2011, $1^{\text {a }}$ edición.

CARNEROS DE Blas, María, "Mediando en salud, una propuesta de mediación sanitaria en hospitales", Revista de Mediación, 2012, $\mathrm{N}^{\circ}$ 5, pp. 13-18.

CHARON, Rita, "Narrative medicine: A model for empathy, reflection, profession and trust”, JAMA, 2001, Vol. $286 \mathrm{~N}^{\circ} 15$, pp. 18971902.

COnstantino, Cathy; SiCKLes, Christina, Diseño de sistemas para enfrentar conflictos, Granica, Barcelona, 1997, traducción de la primera edición por Gabriel Zadunaisky. 2008.

DíEz PicAzo, Luis, El escándalo del daño moral, Civitas, Madrid, 
DomíngUEZ ÁGUILA, Ramón, “Consideraciones en torno al daño en la responsabilidad civil: Una visión comparatista”, Revista de Derecho Universidad de Concepción, 1990, Nº 188.

GuTIÉRREZ ARAQUE, María José, "La mediación en salud y acceso a la justicia”, Revista de Derecho Consejo de Defensa del Estado, 2008, N $^{\circ}$ 20, pp. 111-135.

LEIVA LÓPEZ, Alejandro, "Sobre la inconstitucionalidad de la figura de la "mediación” obligatoria contenida en el artículo 43 de la ley 19.966 (Comentario con ocasión de la sentencia del Tribunal Constitucional Rol 2042-2011 del 10 de julio de 2012, Revista de Derecho Público Iberoamericano, 2012, $\mathrm{N}^{\circ}$ 1, pp. 273-281.

Montaner AbÁsolo, M. Carmen; Soler Company, Enrique, "La relación con el paciente desde la perspectiva personalista. Saber comunicar, un imperativo ético", Cuadernos de Bioética, 2012, Vol. 23 Nº 79, pp. 632633.

Milos Hurtado, Paulina y Siebel Bierwirth, Claudia, "El procedimiento de mediación establecido en la ley $\mathrm{N}^{\circ} 20.584$ ”, Cuadernos de extensión jurídica, 2014, № 25, pp. 96-106.

NogueIRa AlCALÁ, Humberto, El debido proceso en la Constitución y el sistema interamericano, Librotecnia, Santiago, 2012.

Palomo Vélez, Diego; Valenzuela Villalobos, Williams, "Descarte de la inconstitucionalidad de la obligatoriedad de la mediación prejudicial que establece la ley 19.966: lectura crítica de la sentencia del Tribunal Constitucional”, Revista Ius Et Praxis, 2012, año 18 № 2, pp. 387-426.

Parra Sepúlveda, Darío, "La evolución ético-jurídica de la responsabilidad médica”, Acta Bioethica, 2014, Vol. 20 N² 2, pp. 2072013.

PARRA SEPÚlVedA, Darío, "La obligación de informar al paciente. Cuestiones sobre el derecho a ser informado", Revista médica de Chile, 2013, Vol. 141 N$^{\circ}$ 141, pp.1578-1583.

PIZARRO Wilson, Carlos, La responsabilidad civil médica, Legal Publishing Chile, Santiago, 2017.

PIZARRO Wilson, Carlos, "Controversias jurisprudenciales de la responsabilidad de los servicios públicos de salud”, en: De la Maza G., Iñigo (comp.), Cuadernos de análisis jurídico, Ediciones Diego Portales, Santiago de Chile, 2010, Nº 6 Serie Colección Derecho Privado, pp. 187198. 
VARgas PaVez, Macarena, "Caso Pamela de las Mercedes Bahamondes Moreno. Tribunal Constitucional. Sentencia de 10 de julio de 2012”, Revista Chilena de Derecho Privado, 2013, № 20, pp. 309-316.

VICENTE DOMINGo Elena, “El daño”, en: Reglero, F. (ed.), Tratado de Responsabilidad Civil, Aranzadi, Navarra, 2008.

VINEY, Geneviève; JouRDAIN, Patrice, Traite de droit civil: Les effets de la responsabilité, L.G.D.J, Paris, 2001, $2^{\mathrm{a}}$ ed. 